\title{
A presença feminina na docência e nos palcos do Rio de Janeiro oitocentista
}

\section{The female presence in the teaching and on the stages of Rio de Janeiro in nineteenth century}

https://doi.org/10.34112/2317-0972a2019v37n77p65-81

\section{Patricia Amorim de Paula ${ }^{1}$}

RESUMO: Este estudo propõe um exame histórico-sociológico sobre o trabalho musical feminino nos anos 1808 a 1899 e sua contribuição para a formação das novas gerações de músicos e musicistas brasileiros. Para tanto, faz uso de pesquisa documental, tendo como fontes: jornais, biografias, dicionários e enciclopédias de música, obras literárias, cartas, obras de história da música e também do Brasil, entre outros documentos relevantes à temática. A questão que motiva esta análise é: por que a música ocupou lugar central na educação feminina oitocentista no Rio de Janeiro? A partir dela anuncia-se como o ensino de música passou a fazer parte do plano de estudos para uma educação feminina e como o trabalho das professoras estrangeiras e brasileiras de piano e de canto tornou-se fundamental para essa realização.

PalavRas-ChAVE: Educação feminina; musicistas; século XIX.

ABSTRACT: This article presents a historical-sociological view about the musical work of women from 1808 to 1899 and its contribution to the formation of the next generations of Brazilian musicians. Our focus was documental research of different sources: newspapers, biographies, dictionaries and music encyclopedias, literary works, letters, works of Musical History and also Brazilian History, between other documents relevants to the theme. The

1. Universidade Estadual de Campinas, Campinas, SP, Brasil. 
question that guides the analysis is: why music occupy such a central place in the education of women in Rio de Janeiro of the nineteenth century? From this question it is announced how music education becomes part of the study plan for a feminine education, as well the work of foreign and Brazilian piano and singing teachers became fundamental to this realization.

KEYWORDS: Women education; women musicians; XIX century.

\section{INTRODUÇÃO}

A constituição de grupos sociais artísticos brasileiros entre os anos 1808 e 1899 na província do Rio de Janeiro e as condições históricas nas quais se configuraram a formação e o trabalho na música, com a participação social de ambos os sexos, compõem um problema eminentemente sociológico, que carece sempre de reflexão. Este trabalho propõe um exame histórico-sociológico da participação feminina no cenário musical carioca do período e sua contribuição para a formação das novas gerações de músicos e musicistas a partir do século XIX.

A intensa atividade de educação musical, as programações de concertos e os serviços editoriais de música que demonstram os anúncios do Jornal do Commercio, bem como de outros periódicos no período pesquisado, são indicativos de uma ambiência favorável à circulação dessas mulheres musicistas, profissionais e amadoras. Sua atuação profissional se dava do ambiente doméstico das casas-grandes (com as aulas particulares) aos salões aristocráticos (nos saraus e nos bailes), nos concertos em teatros e clubes e em espaços sociais mais restritos, como os colégios. Esse tipo de atividade feminina indica ainda um expediente comum entre as mulheres que, de alguma maneira, precisavam garantir seu sustento, por uma necessidade imposta por sua origem social, ou pela condição de imigração ou por uma fatalidade qualquer - endividamento familiar, falência ou perda de um parente - que as teria feito perder seus bens originais.

É preciso dizer que a possibilidade de inscrição profissional feminina por meio do magistério e da música constituiu um avanço em seus modos de vida². Afinal, essas mulheres viviam numa sociedade de caráter patriarcal e estrutura estamental-escravista ${ }^{3}$,

2. Sempre que utilizarmos o termo modos de vida, estaremos nos referindo à cultura como um processo social geral de preenchimento completo da vida social, o qual se constrói com base na experiência. Trata-se de uma escolha teórica inspirada em Raymond Williams (2007, p. 2011).

3. Sobre a situação estamental-escravista do Brasil Império, ver as sínteses de Alexandro Henrique Paixão (2017, p. 23). 
que negava os direitos às mulheres, sobretudo o direito ao trabalho às mulheres das camadas sociais média e alta.

Como instância de consagração, a historiografia musical escrita por homens pouco abordou essa temática. Nesse sentido, ao se interrogar sobre a história da participação social das musicistas no Brasil oitocentista, é preciso considerar todas e quaisquer pistas, indícios e vestígios que permitam acessá-las (GINZBURG, 2007).

Em busca desses vestígios, debruçamo-nos sobre algumas obras historiográficas que dão ênfase à presença feminina na história oficial. Referimo-nos aos trabalhos de Dalila Vasconcellos de Carvalho (2012), Emília Viotti da Costa (2007), Heleieth Saffioti (2013), Ina von Binzer (1994), Mary Del Priore (2008) e também à antologia de textos de viajantes estrangeiros sobre a condição feminina no contexto carioca oitocentista organizada por Miriam Moreira Leite (1984).

O uso de palavras-chave na análise sociológica do passado permite também dar ênfase ao vocabulário geral que uma dada sociedade compartilhava nas suas mais variadas áreas de reflexão e de experiência. É a porta de entrada para compreender os processos centrais da vida em comum num outro momento histórico. Trata-se de um método de investigação que se inspira nas análises de Raymond Williams (2007) sobre o contexto inglês, mas que foi reorientado para compreender como os processos sociais e históricos se constituíram no interior da cultura impressa do Brasil oitocentista.

A partir das palavras-chave "compositora", "musicista", "pianista" e "professora de piano", desenvolvemos uma pesquisa documental no acervo do Jornal do Commercio, na qual encontramos 48 nomes de mulheres que se ocupavam da atividade de ensino de piano e de canto e 95 nomes de compositoras no mesmo período. Cabe lembrar que havia mais mulheres, para além das 48 referidas, contudo elas não se apresentavam com seus nomes verdadeiros ou artísticos, por isso não pudemos contabilizá-las. Todavia, ao registrar o trabalho e as obras daquelas que se apresentavam com nome, estaremos de alguma maneira nos remetendo ao modo de vida de um grupo de artistas mulheres como um todo.

Antes de iniciar a descrição e a análise desse grupo social específico, faremos uma breve síntese das mudanças atinentes à educação feminina e sua institucionalização pela via oficial e privada; à educação informal desempenhada por professoras estrangeiras; e à apropriação dos modos de vida europeus, a partir do momento em que a província do Rio de Janeiro se tornou Capital do Reino Unido de Portugal, Brasil e Algarves. O intuito será o de justificar a relevância do ensino de música, 
de línguas estrangeiras e de humanidades como parte do plano de estudos de uma educação feminina, mas a ênfase será sobre a música.

\section{BREVE BALANÇO DAS CONDIÇÕES DE VIDA DAS MULHERES OITOCENTISTAS NA PROVÍNCIA CARIOCA}

A educação doméstica sediada no seio familial foi a principal forma de instrução feminina até o século XIX, visto que as instituições de ensino, laicas ou leigas, públicas e privadas, eram ainda escassas e raras. Os saberes cultivados nessa educação caseira desempenhada especialmente pela figura materna, mas também por mestres ou mestras, religiosos ou não, atuantes nas residências, não iam muito além da leitura do livro de rezas, e também não era fomentado que escrevessem, pois poderiam fazer mau uso dessa arte; a conversação era um hábito estimulado, e recitar preces de cor, fazer cálculos de memória, coser e trocar receitas fazia parte de seus lazeres (LEITE, 1984).

Para um entendimento mais amplo dessa educação doméstica, é preciso compreender que a principal base da socialização feminina era a família. A família patriarcal, celebrada pela instituição do casamento, unia homem e mulher numa formação nuclear, atribuindo uma função específica a cada um: para o homem atribuía o papel de provedor, cujo trabalho era realizado fora do lar; para a mulher restava o papel de colaboradora com um comportamento submisso, e seu trabalho era prioritariamente no lar, em afazeres domésticos e na educação da prole, embora as mulheres pobres também realizassem atividades comerciais e de serviços em âmbito externo (SAFFIOTI, 2013).

Para a mulher, em geral, o peso dessa forma de socialização colaborou para a aceitação de sua posição subalterna, bem como para a crença na autoridade patriarcal por parte de todos os submetidos à autoridade familiar na ordem escravocrata. Trata-se do poder doméstico organizado com base numa estrutura patriarcal de dominação, conforme elaborou teoricamente Max Weber (WEBER, 1999).

Com a chegada da corte portuguesa ao Brasil em 1808 e a imediata abertura dos portos, algumas oportunidades de instrução laica para a mulher se tornaram possíveis, por meio da iniciativa de senhoras portuguesas e francesas que recebiam as moças em suas casas como pensionistas (SAFFIOTI, 2013). Debret (1816 apud LEITE, 1984, p. 70) faz referência a esses casos em seu relato: 
Os dotes mais apreciados na sociedade são os da dança e do canto, porque permitem brilhar nas reuniões. Na alta sociedade exige-se também música, principalmente piano, bem como o conhecimento das línguas francesa e inglesa e de desenho. As moças aprendem com facilidade a traduzir e a escrever a língua francesa, mas encontram em geral certa timidez em falá-la.

Segundo Heleieth Saffioti (2013), embora tenham sido iniciativas isoladas, foi com a vinda dessas senhoras francesas, portuguesas e, posteriormente, alemãs que outras experiências educacionais foram proporcionadas à mulher brasileira. De fato, se pensarmos simplesmente na ampliação do conteúdo a ser ensinado, incorporando saberes artísticos, sobretudo musicais, e as línguas estrangeiras, fica evidente uma substantiva alteração nos modos de vida femininos. Contudo, algumas conquistas educacionais mais sistemáticas para o público feminino, a partir da criação de marcos regulatórios e de instituições, foram fundamentais para o princípio da construção de uma política pública educacional ${ }^{4}$.

Saffioti (2013, p. 281) destaca a seguinte organização do ensino a partir da segunda metade do século XIX no município da Corte:

[...] havia, em 1855, 17 escolas primárias para meninos e apenas nove para meninas; 909 alunos e 553 alunas frequentavam essas escolas. A rede particular de instrução mantinha, nesse mesmo ano, 97 estabelecimentos educacionais entre escolas e colégios, dos quais 51 se destinavam à população masculina e eram frequentados por 4.490 alunos e 46 ao sexo feminino, registrando-se a frequência de 2.864 alunas. Em 1861, a frequência às escolas oficiais de primeiro grau se elevara para 1.892 alunos contra 1.091 alunas. Quatro anos depois essa diferença sofria redução (1.860 alunos contra 1.530 alunas),

4. Apontamos resumidamente algumas medidas: a lei do governo imperial de 1823 , que criou escolas primárias para meninas e meninos nas cidades e nas vilas mais densamente povoadas (COSTA, 2007, p. 507) e a primeira Constituição do Brasil independente, a Imperial de 1824, na qual fica prevista a instrução primária gratuita a todos os cidadãos (OLIVEIRA; ADRIÃO, 2001, p. 15). No ensino secundário feminino, pela ausência de escolas públicas neste nível para esse público, a continuidade dos estudos se dava por meio de instituições particulares no País ou na Europa, o que excluía, desse modo, amplo contingente de mulheres; a instrução secundária privada envolvia altos custos para o público comum. Segundo o Almanaque Laemmert de 1863 , a anuidade das escolas particulares variava entre $100 \$ 000$ e $500 \$ 000$ - preço equivalente, na época, à compra de um escravo e/ou de um piano. Quanto à inserção feminina nos cursos superiores no País, podemos dizer que foi uma conquista dos anos finais do século XIX. A inexistência de uma rede oficial de ensino secundário que abarcasse as moças era um forte impeditivo para o acesso a carreiras superiores possíveis na Corte, como direito e medicina. 
mas seria nas escolas particulares que a quase igualdade numérica seria alcançada: $\mathbf{2 . 1 1 1}$ alunos do sexo masculino e 2.056 do sexo feminino. Este processo, por meio do qual a mulher acabaria por obter a paridade com o homem no ensino, entretanto, não se desenvolveu homogeneamente, registrando-se um retrocesso em 1866, quando 2.863 alunos frequentavam as escolas particulares contra 2.080 meninas.

Em momento posterior, Émile Allain (1886 apud LEITE, 1984, p. 80) apresenta os seguintes dados referentes à província do Rio de Janeiro:

O ensino primário particular está distribuído em estabelecimentos, dos quais a maior parte tem cursos de instrução secundária. O número deles, em 1884, era de 185, dos quais 27 subvencionados pelo Estado. Deste número 77 são para o sexo masculino, 53 para o sexo feminino e 55 mistos. Em 1883, foram frequentados por 10.064 alunos, 6.710 do sexo masculino e 3.354 do sexo feminino. A frequência média foi de 7.375. A municipalidade mantém também algumas escolas e o soberano, duas, a da quinta de São Cristovão e a da fazenda imperial de Santa Cruz.

Embora estejamos falando em conquistas pouco expressivas do ponto de vista numérico, sobretudo para a instrução primária, não podemos perder de vista que esse foi o princípio da construção de uma política pública educacional.

Os dados supracitados comprovam o quão significativo e necessário foi o papel das educadoras estrangeiras que atuavam de modo informal nas casas de famílias bem estabelecidas ou em suas próprias residências. Elas chegaram a locais em que as escolas oficiais ou particulares, laicas ou leigas, não tiveram condições de se estabelecer e atendiam, sobretudo, as meninas das camadas média e alta da zona rural, que tinham limitadas oportunidades educacionais nos raros internatos existentes no País ou na Europa.

É preciso mostrar para o leitor quais eram os conteúdos abordados nessa educação voltada ao público feminino tanto nas escolas quanto de maneira informal, em âmbito doméstico. Esse movimento será fundamental, pois fornecerá elementos para reflexão posterior sobre a questão: por que a música ocupou lugar central na educação feminina oitocentista no Rio de Janeiro?

Primeiro, vejamos o que diziam os viajantes estrangeiros, E. Belman (1825) e Charles Expilly (1853), respectivamente, sobre os conteúdos a serem aprendidos pelas moças brasileiras, para que fossem consideradas bem-educadas: 
No Brasil, a moça bem educada, de boa formação (uma moça muito prendada) é aquela que com um pouco de música e de francês, sabe dançar um solo inglês, sabe bordar, fazer crochê e conhece a difícil arte de descascar, com gosto, uma laranja. (BEHLMAN apud LEITE, 1984, p. 71)

Hoje, ainda, a educação de uma brasileira está completa, desde que saiba ler e escrever correntemente, manejar o chicote, fazer doces e cantar acompanhando-se ao piano, num romance de Arnaud ou de Luíza Puget. Até agora as senhoras não tomaram da civilização senão a crinolina, o chá e a polca. (EXPILLY apud LEITE, 1984, p. 73)

Agora, vejamos os anúncios de época sobre as matérias necessárias para completar a educação de uma senhora. Apresentamos anúncios de colégios distintos, em momentos históricos diferentes, no entanto, situados no mesmo lugar. Primeiro, o Collegio de Santa Cecilia para meninas (1858); segundo, o Collegio União Infantil para meninas $(1899)^{5}$.

\section{COLLEGHO DE SANTA CECLLIA \\ PARA MENINAS, \\ Tura do Ouvidor n. 38 .}

A directora deste estabelecimento tem a honra $i \theta$ fazer publico que os estudos interrompidos pelas ferias começarão de novo no dia 7 de janeiro. Além da instrucçăo primaria lecciona-se francez, inglez, geographia, piano, canto, dança e desenho, tudo por precos muilo moderados, e para o que tem habeis e bem morigerados professores, como sejam os Srs. Burgain, condessa de Rozwadowska e outros.

Continúa-se a receber pensionistas $\theta$ meias pensionistas e externas. - A directora, Theresa de Jesus Araujo Sampaio.

Figura 1 - Jornal Diário do Rio de Janeiro (Rio de Janeiro), Edição oooo2, 1858.

5. Estamos cientes da distância temporal e do correr dos acontecimentos que envolvem ambos os períodos nesses distintos colégios. Todavia, nosso intuito aqui é apenas evidenciar as permanências, o que perdurou como legado curricular nessa passagem do tempo. 


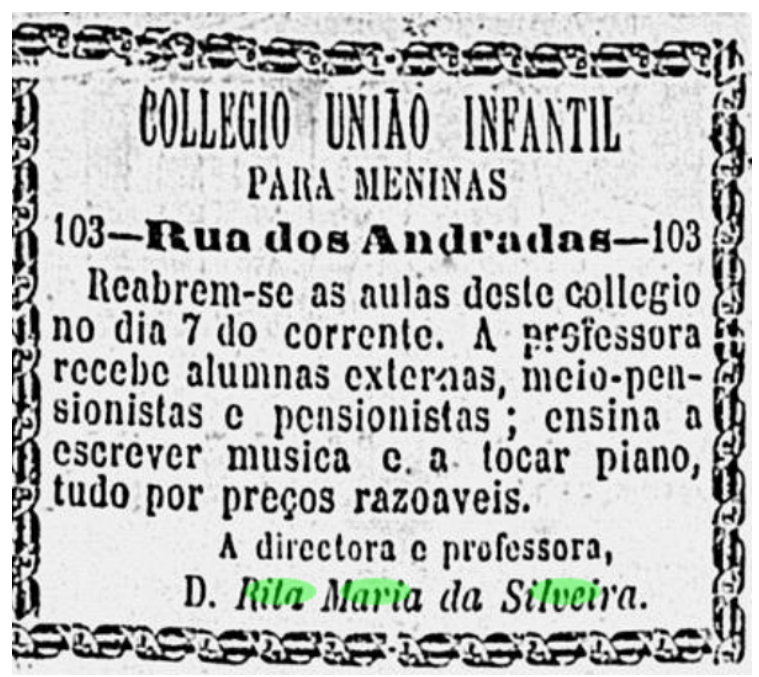

Figura 2 - Jornal O Paiz (Rio de Janeiro), Edição 05206, 1899

Por último, trazemos trechos das cartas de uma professora alemã de línguas estrangeiras (alemão, inglês e francês) e de piano e canto, cujo nome é Ina von Binzer. Ela relata sua rotina de trabalho num colégio para moças em 1882 e na fazenda de Madame Rameiro, respectivamente:

[...] desde anteontem estou contratada para um colégio daqui. Um colégio é um liceu de moças, com pensionato; tenho que lecionar quatro classes, iniciando as filhas deste país nos segredos das línguas alemã e inglesa; além disso darei inúmeras aulas de piano. [...] Com a melhor boa vontade não cheguei ainda a calcular o número das minhas alunas de música. Quando me sento ao piano pela manhã, às seis e meia, elas começam a aparecer de meia em meia hora, até as dez horas, como se fossem expelidas por um relógio automático. Agora, tenho tomado nota de uma a uma, e à força de muito trabalho e astúcia espero estabelecer um cálculo exato (BINZER, 1994, p. 81-82).

Aqui, as aulas são das sete às dez, depois vem o almoço quente, pelo qual Madame Rameiro nos faz esperar inutilmente até às dez e meia, de maneira que não posso mais sair, porque, logo após o último bocado, tenho de voltar às aulas. Prosseguimos até uma hora, quando temos então trinta minutos para o lanche; à uma e meia começam as aulas de piano que vão até às cinco, quando servem o jantar. Pergunto-lhe eu: quando 
poderei passear antes das seis? Veja se consegue descobrir outra hora melhor. Eles querem engolir cultura às colheradas e nunca têm uma tarde livre, um dia desocupado, nem muito menos uma semana de férias durante todo o ano (BINZER, 1994, p. 31 ).

Os distintos documentos parcialmente transcritos sobre o período analisado apontam para os mesmos conteúdos curriculares previstos para a educação de uma senhora com boa formação, considerando um recorte temporal de 1825 a 1899, na província do Rio de Janeiro. O que interessa, ao frisar essas passagens, é que o ensino de piano e de canto era um tema central nessa sociedade, no que diz respeito às condições de vida das mulheres.

Outras oportunidades educacionais foram facultadas às mulheres; as Escolas Normais, por exemplo, lhes asseguravam a continuidade dos estudos e o acesso à profissão docente. Dain Borges (1992) nota que, em 1856, 15\% dos cargos em escolas públicas eram ocupados por mulheres, e em 1890 a porcentagem subiu para $56 \%$ (COSTA, 2007, p. 505).

Esse fato merece a nossa atenção e reflexão; afinal, numa sociedade que praticamente negava o direito ao trabalho às mulheres das camadas sociais média e alta, paulatinamente, a partir da segunda metade do século XIX, o magistério passou a anunciar uma possibilidade de inscrição profissional feminina, com ampla adesão e progressivo estímulo social.

O fato é que foi se construindo uma espécie de vocação clérigo-leiga feminina no exercício do magistério, e ela era benéfica para o curso das mudanças que ora se delineavam, além de satisfatória para a conservação da ordem patriarcal e para a coesão social. A função feminina atribuída pelo casamento e pela maternidade não estaria ameaçada pelo exercício da docência como trabalho de um turno. A essa vocação clérigo-leiga estariam associadas: a forte influência religiosa católica que esteve presente em boa parte das instituições educativas voltadas ao público feminino; uma espécie de estímulo ao desapego material na profissão, em que questões ligadas ao salário, à carreira e às condições de trabalho podiam ficar em segundo plano; e, por último, "atributos ditos femininos", como: paciência, minuciosidade, afetividade, doação, cuidado, sensibilidade e amor (LOURO, 2008, p. 450-454).

$\mathrm{O}$ que precisamos reter desse conjunto de informações que nutrem o fazer professoral feminino são os investimentos sociais a ele dispensados, o que mostra que a palavra-chave professora fazia parte do expediente comum carioca da segunda metade do século XIX. Outro dado que se soma a isso é que o Imperial Conservatório 
de Música do Rio de Janeiro, fundado em 1848 por Francisco Manuel da Silva (17951865), desde o início de suas atividades esteve aberto ao público feminino, embora não tivesse nenhuma professora em seu quadro (CARVALHO, 2012). Logo, os espaços de profissionalização feminina garantidos pela oficialidade tinham como matérias principais: o magistério e a música. Chegamos a mais um indício de que ser professora de música também era uma palavra-chave da época.

Contudo, o debate sobre a profissionalização feminina e sobre o direito à educação que começou na segunda metade do século XIX se manteve forte. De certo modo, todo esse legado foi se construindo a partir da chegada da Corte portuguesa ao Brasil, com a maior vivência da cultura material experimentada por mulheres de países europeus, as transformações ocorridas nos modos de vida urbanos, a delimitação das vivências familiares e domésticas e o ambiente externo (a rua e os espaços públicos) - tudo isso, inspirado numa mentalidade burguesa (D’INCAO, 2008).

A maior delimitação dos espaços privados e públicos foi um marco do desenvolvimento das cidades e dos estilos de vida cortesão e burguês durante o século XIX. A maior disposição do espaço no interior da residência, garantindo mais privacidade e liberalidade das emoções, e a interiorização da vida doméstica se deram concomitantemente à abertura das casas mais refinadas aos momentos de divertimento público, porém restrito a um grupo social que partilhava de costumes em comum. Assim, as salas de visita e os salões - espaços intermediários entre o lar e a rua -, locais que sediavam os saraus noturnos, os jantares e as festas, como espaços de convívio social, arranjos diversos e negociação diplomática, abriram caminhos para que as mulheres, antes isoladas e privadas desse tipo de prazeres, pudessem então partilhar desses momentos, como também de outras vivências em ambientes externos ao lar - em cafés, bailes e teatros (D'INCAO, 2008).

As leituras em voz alta de trechos de poesia e romances, bem como as conversações sobre as notícias correntes, exigiam certo domínio da leitura e conhecimento literário. $\mathrm{O}$ canto acompanhado de piano ou harpa e também a execução de outros instrumentos usuais no período determinavam certo domínio de saberes musicais especializados. Podemos acrescentar a isso a conversação em língua estrangeira, como o francês, $o$ inglês e $o$ alemão, marcadores sociais de uma educação feminina refinada, capazes de impressionar e obter bons casamentos, dentro do bojo das exigências aplicadas às mulheres no período.

Estamos diante de uma nova função da mulher nessa sociedade, a partir da segunda metade do século XIX: "contribuir para o projeto familiar de mobilidade social 
através de sua postura nos salões como anfitriãs e na vida cotidiana, em geral, como esposas modelares e boas mães" (D'INCAO, 2008, p. 229). A elaboração teórica feita por Maria Ângela D’Incao corrobora uma possível resposta para a questão: e por que a música ocupou lugar central na educação feminina oitocentista? Porque a educação feminina brasileira das camadas média e alta precisava ser equiparável à educação feminina europeia, para que as mulheres pudessem colaborar com o projeto familiar de mobilidade social, por meio de sua postura nos salões, nos saraus e nos bailes.

Com o crescente fluxo migratório que se seguiu, ao longo do século XIX, e o estímulo a relações conjugais não mestiças, essa educação lhes garantiria bons casamentos e alianças rentáveis no País - melhor ainda, casamentos com famílias de estrangeiros que vieram ao Brasil para investir na potência em construção; parece que temos aí uma boa hipótese para a presença musical tão marcante nessa educação. Além disso, formar as senhoras nacionais dentro dos padrões europeus de educação feminina se anunciava como um investimento premente para a formação de futuras gerações no País, ao passo que a presença de professoras estrangeiras no cumprimento dessa função era insuficiente e ineficaz, se pensada a longo prazo, em razão da instabilidade de seus vínculos na nação estrangeira.

\section{A atuaÇão MUSiCAL FEMINina Na doCÊnCIA E NOS PALCOS: CONTRIBUIÇÕES PARA UMA EDUCAÇÃO FEMININA POR MEIO DO PIANO E DO CANTO}

Os passos seguidos até aqui mostraram a relevância do ensino de música no plano de estudos de uma educação feminina. Agora veremos mais detidamente quem eram as artistas responsáveis por esta educação, o que faziam e como faziam. Para tanto, realizamos uma pesquisa no Jornal do Commercio (Rio de Janeiro) e em outros periódicos da época, conforme já anunciado.

As mulheres que encontramos nesta pesquisa eram contratadas não somente como professoras de piano e de canto (modo como se apresentavam nos anúncios), mas como professoras de línguas estrangeiras (francês, português, alemão e italiano), de humanidades (história, geografia, primeiras letras e desenho), de trabalhos de agulha (bordados) e também como governantas nas casas de boa reputação. Eram, em sua maioria, estrangeiras, mulheres idosas, de meia idade, viúvas ou jovens solteiras, recém-chegadas ao Brasil. Mas, a partir da segunda metade do século XIX, mulheres brasileiras passaram a desempenhar essa função. Geralmente, 
ofereciam seus préstimos ou eram procuradas para atuar em colégios internos, em casas particulares ou em sua própria residência, e tinham como público alvo meninas das chamadas "boas famílias". Essas artistas se comprometiam a oferecer todas as matérias necessárias para a educação de uma senhora da alta sociedade, tendo como referência os padrões europeus burgueses da época. ${ }^{6}$

Elas apresentavam seus anúncios de trabalho ou eram procuradas geralmente nas páginas destinadas aos anúncios diversos, tais como: venda, aluguel e recompensa pela captura de escravos fugidos, divulgação de serviços e produtos relacionados à saúde e à higiene, leilóes diversos, serviços relacionados ao comércio de alimentos, serviços e produtos relacionados ao vestuário, aluguel de imóveis e de pessoas para trabalhos eventuais em residências e no comércio. A esse respeito, a professora de piano alemã, Ina von Binzer (1994, p. 67), fez um importante comentário: "[...] ando procurando no Jornal do Comércio o que me possa servir, entre os anúncios de pretos fugidos e vendas de escravos, que é onde também se pedem as professoras com imensa capacidade e inúmeras perfeições”.

Pela forma de apresentação dos anúncios, pelos seus enunciados, identificamos a presença de distinções entre essas mulheres. Enquanto algumas delas estavam associadas à figura de grandes mestres e músicos de alto prestígio de seu tempo (Achille Arnaud, Sigismond Thalberg, Gennaro Arnaud, Henrique Herz e Louis Moreau Gottschalk, Arthur Napoleão, Archangelo Fiorito, Isidoro Bevilacqua, por exemplo), possuíam um currículo que expressava uma formação canônica ${ }^{7}$ e apresentavam-se na cena pública em concertos nos teatros e nos salões, as outras eram tão somente professoras de piano anônimas, que se apresentavam pela escrita: "senhora", "viúva", "professora de piano" ou "mestra idosa”, cujos termos revelam muito pouco sobre sua identidade. Assim as hierarquias se organizavam entre as musicistas de maior prestígio e as musicistas corriqueiras.

6. Jornal do Commercio, Edição o0224, 1838; Jornal do Commercio, Edição 00296, 1852; Jornal do Commercio, Edição o0128, 8 de maio de 1860; Jornal do Commercio, Edição o0301, 1861; Jornal do Commercio, Edição oo183, 2 de julho de 1864 .

7. A ideia de cânone musical, segundo William Weber (WEBER, W., 1999), é o que revela os preceitos mais básicos de como a música funciona como disciplina, ditando como o indivíduo aprende dentro deste campo, como ele internaliza certos padrões e como não pode transgredi-los. $\mathrm{O}$ autor destaca num processo de longa duração, do século XVI ao século XX, como interagem as quatro principais bases intelectuais do cânone: $o$ ofício, o repertório, a crítica e a ideologia. A performance atuou na função de consagração de cânones, foi ela quem conferiu a chancela ao cânone, ao ponto que até um público menos versado pode reconhecer padrões da música de Haydn, Mozart, Beethoven e Brahms entre composições contemporâneas, por exemplo. Quando falamos de uma formação canônica, são esses os princípios considerados. 
Embora fosse do interesse da maioria das professoras que pesquisamos filiar-se aos colégios para ministrar o ensino de piano e de canto, identificamos somente alguns nomes associados a instituições educacionais cujo público alvo era, em sua maioria, o feminino. São eles: Clara Freese Tiberghien (Diretora e Professora do Collegio das Laranjeiras para meninas), Claudina de Paula Menezes (Professora da 2. ${ }^{a}$ cadeira no Magisterio Publico Primario da freguezia de S. José para o sexo feminino), Condessa de Rozwadowska (Professora no Collegio de Santa Cecilia para meninas), Sophia Emery (Professora no Collegio da baroneza de Geslin), Candida Francisca de Andrade (Collegio Braga e Collegio Costa Pereira) e Rita Maria da Silveira (Diretora e Professora do Collegio União Infantil).

Theodolinda Gerly não esteve associada a uma iniciativa institucionalizada de ensino, porém, após ter concluído seu contrato com a companhia de Ópera Lírica instalada no Theatro Lyrico, organizou em sua residência um curso de música com método próprio, aprendido com o Professor P. Bona, do Conservatório de Milão. Ela se dedicou ao ensino de discípulas particulares e também às meninas pobres que desejassem aprender gratuitamente a tocar piano e cantar. Encontramos vários anúncios fazendo menção ao fato e, inclusive, informando que as aulas se davam simultaneamente para pagantes e não pagantes, o que já nos assinala a ausência de distinção no tratamento dado às suas alunas. Além disso, promovia anualmente concertos com suas discípulas e com artistas convidados. Tal iniciativa demonstra certamente um impacto público do seu trabalho, independentemente de ele estar vinculado a uma instituição. Temos duas matérias que fazem menção ao fato, e a última fala sobre um concerto dado com suas discípulas e artistas convidados, como uma forte evidência da eficácia de seu método perante o público ouvinte. ${ }^{8}$

Quanto aos métodos de ensino de piano e de canto, alguns anúncios demonstraram que as referências utilizadas eram europeias, ligadas à formação da professora (Método repentino de P. Bona, do Conservatório de Milão, utilizado por Theodolinda Gerly; e Método Maersch, utilizado por Rafaela Rozwadowska, por exemplo), incluindo métodos próprios. Outro ponto que chama a atenção é a propaganda sobre a rapidez com que as aprendizes desenvolveriam a técnica necessária para tocar piano e cantar, bem como para escrever música. Essa informação reitera a importância dessa formação para as senhoras, o lugar da música nessa sociedade,

8. Correio Mercantile Instructivo, Politico, Universal, 1858, Edição oo122; Diario do Rio de Janeiro, 9 de novembro de 1861, Edição 00306. 
sobretudo da música que se podia fazer ao piano, e a acirrada concorrência ao posto de professora de piano. Soma-se a isso o fato de que elas acumulavam múltiplos trabalhos para garantir sua subsistência: eram professoras, intérpretes e compositoras.

O que movia o fazer artístico dessas mulheres não era o ideal romântico de artista e virtuose, mas a necessidade de sobrevivência. Sendo elas "bem-nascidas" ou não, no geral, era a instabilidade econômica de suas vidas que mobilizava seus trabalhos artísticos - é o que aponta a trajetória da Condessa Rafaela de Roswadowska, por exemplo.

A Condessa Rafaela de Roswadowska merece destaque, pois compôs a primeira ópera escrita por uma mulher no Brasil (Dous Amores, drama lyrico em três atos, 1861). De origem polonesa, era esposa do Conde de Roswadowsky, cidadão brasileiro, ex-major do Estado Maior do nosso exército, residente no Rio de Janeiro (AZEVEDO, 1938). Além da ópera, localizamos cinco composições para piano e um hino de sua autoria. Entre os anúncios, havia também uma recorrente oferta de suas aulas de piano, de canto, de composição e de italiano e sua presença como concertista em importantes teatros cariocas de seu tempo, o que aponta uma necessidade, por parte dela, de ter uma boa remuneração, atuando em várias frentes. $O$ anúncio a seguir demonstra a necessidade dessa artista de se destacar em relação às demais, ressaltando suas qualidades e seu nome.

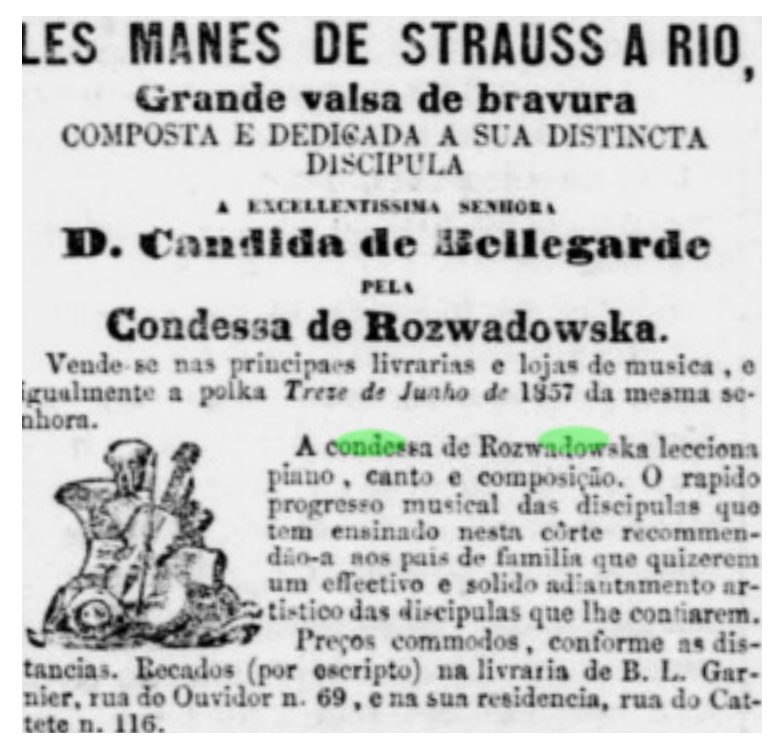

Figura 3 - Jornal do Commercio, Edição oo172, 1857 
O esforço deste trabalho consistiu em esculpir o esboço de um perfil feminino das musicistas descobertas entre os anúncios do Jornal do Commercio. A análise nele desenvolvida pretendeu interpretar alguns sinais de vida dessas mulheres, obscurecidos por um universo musical predominantemente masculino. Note-se que a prerrogativa da formação canônica que muitas delas compartilhavam está centrada no legado masculino. Entretanto, nessa perspectiva, Marcia Citron (CITRON, 1993) discute como o conjunto de expectativas autoimpostas se diferencia para homens e mulheres profissionais da música; geralmente, as mulheres estão menos presas aos padrões canônicos, mais liberadas para a escrita e a execução de gêneros intelectualmente menos ambiciosos e mais populares, o que se justifica nesse caso porque elas buscavam incessantemente sobreviver por meio da música e encontravam-se em relação desigual perante os homens.

Outro aspecto significativo é que a inscrição profissional dessas mulheres e o ensino de música por elas desempenhado promoveram algo para além da imagem dominante que se tinha da mulher carioca oitocentista. Pelo caminho analítico percorrido, vimos que: a promoção da escolarização, o contato com o mundo letrado, a presença do piano nas casas, a frequência nos teatros, nos bailes, nas lojas de música, propiciaram uma reconfiguração da sociedade, no sentido de conservar a base do patriarcado, mas também de expor as ambiguidades, as transgressões ${ }^{9}$ vividas pelas mulheres.

É preciso ter em vista ainda que a tradição e a demanda histórica são aspectos que movem continuamente o fazer artístico musical. Entretanto, como as mulheres musicistas encaram essa demanda histórica, se a tradição que as precede, e da qual se nutrem, permanece permeada pela figura do masculino? É uma questão do passado, mas que sobrevive no presente, e continuaremos refletindo sobre isso.

\section{REFERÊNCIAS}

ALMANAK LAEMMERT: Administrativo, Mercantil e Industrial da Corte e Provincia do Rio de Janeiro para o anno de 1863, fundado por Eduardo von Laemmert, redigido por Carlos Guilherme Haring. Vigesimo Anno (segunda série XIV). Em casa dos Editores-Proprietarios Eduardo

9. Segundo Saffioti e Almeida (1995, p. 178), a transgressão pode referir-se "à construção de contrapoderes e de ressignificação de valores e vivências". 
A presença feminina na docência e nos palcos do Rio de Janeiro oitocentista

\& Henrique Laemmert. Disponível em: <http://memoria.bn.br/DocReader/docreader. aspx $? \mathrm{bib}=313394 \mathrm{x} \&$ pasta $=$ ano\%20186\&pesq $=>$. Acesso em: 20 dez. 2018.

AZEVEDO, L. H. C. Escala, ritmo e melodia na música dos índios brasileiros. Rio de Janeiro: Rodrigues \& $\mathrm{Cia}, 1938$.

BINZER, I. Os meus romanos: alegrias e tristezas de uma educadora alemã no Brasil. Tradução de Alice Rossi e Luisita da Gama Cerqueira. 6. ed., rev. e bilíngue. Rio de Janeiro: Paz e Terra, I994.

CARVALHO, D. V. O gênero da música: a construção social da vocação. São Paulo: Alameda, 2012.

CITRON, M. J. Gender and the musical canon. Cambridge: Cambridge University Press, 1993.

COSTA, E. V. Da Monarquia à República: momentos decisivos. São Paulo: Editora Unesp, 2007.

DEL PRIORE, M. (Org.). História das mulheres no Brasil. São Paulo: Contexto, 2008.

D'INCAO, M. A. Mulher e família burguesa. In: PRIORE, M. D. (Org.). História das mulheres no Brasil. São Paulo: Contexto, 2008. p. 223-240.

GINZBURG, C. Mitos, emblemas, sinais: morfologia e história. Tradução de Federico Carotti. 4. ed. São Paulo: Companhia das Letras, 2007. p. I43-275.

LEITE, M. M. (Org.). A condição feminina no Rio de Janeiro, século XIX: antologia de textos de viajantes estrangeiros. São Paulo: HUCITEC/Pró-Memória, I984.

LOURO, G. L. Mulheres na sala de aula. In: PRIORE, M. D. (Org.). História das mulheres no Brasil. São Paulo: Contexto, 2008. p. 446-468.

OLIVEIRA, R. P.; ADRIÃO, T. (Org.). Gestão, financiamento e direito à Educação: análise da LDB e da Constituição Federal. São Paulo, SP: Xamã, 200 I.

PAIXÃO, A. H. Leitores de tinta e papel: elementos constitutivos para o estudo do público literário no século XIX. Campinas: Mercado de Letras, 2017.

SAFFIOTI, H. I. B. A mulher na sociedade de classes. São Paulo: Expressão Popular, 2013.

SAFFIOTI, H. I. B.; ALMEIDA, S. S. Violência de gênero: poder e impotência. Rio de Janeiro: Revinter, 1995.

WEBER, M. Economia e sociedade: fundamentos da sociologia compreensiva. Tradução de Regis Barbosa e Karen Elsabe Barbosa. Brasília: Editora Universidade de Brasília; São Paulo: Imprensa Oficial do Estado de São Paulo, 1999.

WEBER, W. The history of musical canon. In: COOK, N.; EVERIST, M. Rethinking music. New York: Oxford University Press, 1999. p. 336-355.

WILLIAMS, R. Palavras-chave: um vocabulário de cultura e sociedade. São Paulo: Boitempo, 2007. . Cultura e sociedade: de Coleridge a Orwell. Petrópolis: Vozes, 2011.

SOBRE A AUTORA

Patrícia Amorim de Paula é graduada em Pedagogia (Universidade Estadual de Campinas), tem Mestrado em Educação (Universidade Estadual de Campinas) e 
é Doutoranda em Educação (Universidade Estadual de Campinas) sob a orientação do Professor Doutor Alexandro Henrique Paixão. Tem experiência na área de sociologia da educação, sociologia da cultura, sociologia do trabalho artístico, história cultural e estudos de gênero, com pesquisa nos seguintes temas: formação de músicos, influência religiosa na formação musical, políticas culturais, formação e trabalho das musicistas no Rio de Janeiro oitocentista. É Bolsista da Fundação de Amparo à Pesquisa do Estado de São Paulo (FAPESP).

E-mail:paulaapatricia1@hotmail.com.

Recebido em o1 de julho de 2019 e aprovado em 23 de setembro de 2019. 